\title{
Associations of MTHFR C677T, A1298C and MTRR A66G Polymorphisms With the Risk of Low Birth Weight Infants
}

\section{Shuang Sun}

Central Laboratory of Maternal and Child Health Hospital of Jilin Province Ying Liu ( $\sim$ liuyingss200816@163.com )

Maternal Children Hospital: Hospital of jilin provinceMaterno Infantil https://orcid.org/0000-00017126-2671

\section{Xiaoling Hu}

Central Laboratory of Maternal and Child Health Hospital of Jilin Province

\section{Xuehua Guo}

Central Laboratory of Maternal and Child Health Hospital of Jilin Province

\section{Xun Zhao}

Central Laboratory of Maternal and Child Health Hospital of Jilin Province

\section{Research Article}

Keywords: MTHFR C677T, MTHFR A1298C, MTRR A66G, Low birth weight

Posted Date: February 14th, 2022

DOl: https://doi.org/10.21203/rs.3.rs-998239/v1

License: (c) (i) This work is licensed under a Creative Commons Attribution 4.0 International License. Read Full License 


\section{Abstract}

Background: To explore the relationship between maternal methylenetetrahydrofolate reductase (MTHFR) gene C677T and A1298C, Methionine Synthase Reductase (MTRR) gene A66G and the recurrence of low birth weight(LBW) in offspring.

Methods: Our case-control study enrolled 106 maternal blood samples of premature infants and 168 maternal blood samples of normal births.Allele-specific polymerase chain reaction (ASPCR) assay combined with TaqMan probe technique were used to detect the mother's MTHFR and MTRR genotypes respectively. And unconditional logistic regression analysis was used to evaluate the associations of MTHFR and MTRR polymorphisms, and gene-gene interaction with low birth weight.

Results: MTHFR 677TT and 1298CC were independently associated with a higher risk of LBW (OR:2.22, 95\%Cl:1.14-4.34 and OR:2.82, 95\% Cl:1.15-6.87,respectively). The MTRR A66G polymorphism was associated with an significant association of LBW when combined with the MTHFR 677TT genotype, although there was no association found between LBW and MTRR A66G alone.Moreover, two or more risk genotypes carriers showed higher odds of LBW than null risk genotype one.

Conclusion: Maternal MTHFR gene 677TT, 1298CC can increase the risk of LBW in the offspring.The MTRR A66G polymorphism was not associated with LBW alone. But it may exacerbate the effect of the MTHFR C677T variant.

\section{Background}

Low birth weight (LBW) is an adverse pregnancy outcome which refers to a baby with a birth weight less than $2500 \mathrm{~g}$ [1]. The incidence of low birth weight infants in China is $5.87 \%$ of live births[2]. LBW can lead to a higher mortality rate, and prone to mental retardation and growth retardation[3-4].Most of the LBW is caused by the combination of environmental and genetic factors.Methylenetetrahydrofolate reductase (MTHFR) and Methionine Synthase Reductase (MTRR) are homocysteine (Hcy) key enzymes of the metabolic pathway, the decreased activity of both may lead to hyperHcyemia[5].

Hyperhomocyticemia is considered to have a toxic effect on the development of the embryo[6]. The level of Hcy in maternal blood is affected by the most common mutation sites of its key enzymes including MTHFR C677T,A1298C and MTRR A66G polymorphism.

MTHFR C677T polymorphism associated with thermolability and reduced enzyme activity, leading to accumulation of Hcy especially under conditions of low dietary folate [7].Most studies have shown that the plasma total homocysteine concentration of homozygous (TT) mutant subjects is significantly increased[8-10]. MTRR A66G polymorphism decreases the enzyme activity and the rate of Hcy remethylation, and further affects plasma homocysteine levels[11].MTRR A66G may also induce DNA hypomethylation by regulation of Hcy levels [12]. Moreover, Vaughn JD et al. indicated additive or synergistic effects of the MTHFR C677T and MTRR A66G polymorphisms on plasma Hcy levels [13].Several studies have shown that MTHFR A1298C was a risk factor for neural tube defects and 
combined with C677T resulted in elevated Hcy and decreased plasma folate levels similar to that of 677TT homozygosity[14-16].Gideon Friedman et al. demonstrated that the A1298C mutation affected homocysteine metabolism because the total homocysteine concentration decreased significantly in subjects with 677cc / 1298cc genotype[17].Many epidemiological studies have indicated that the MTHFR C677T, A1298C and MTRR A66G polymorphisms with various diseases, including birth defects, pregnancy complications[18-20]. However,whether gene mutations of key enzymes are related to LBW is unclear.Studies by Diptika Tiwari et al. found that MTHFR C677T is a risk factor associated with the susceptibility of LBW in northeast India based correlation analysis[21].So far, no large-scale, welldesigned epidemiological studies have clearly demonstrated that MTHFR and MTRR variants are related to LBW in northeast China.We therefore conducted a case-control study to investigate the associations of MTHFR C677T, A1298C MTRR A66G on LBW risk.

\section{Materials And Methods}

\section{Subjects}

This study enrolled 106 maternal blood samples of premature infants admitted to the Department of Neonatology, Jilin Province Maternal and Child Health Hospital from April 2019 to April 2021 as the case group.168 maternal blood samples of normal births admitted to obstetrics during the same period were selected as the control group.Maternal inclusion criteria: a.No obstetric complications such as eclampsia, diabetes, placenta previa; $b$.Take multivitamins instead of conventional folic acid during pregnancy. The criteria for selection of case parturients who gave birth to low birth weight infants: a. Gestational age >28 weeks, body weight < 2500 g; b. Normal delivery, exclude premature babies caused by accidents; c.Eliminate twins or multiple births and congenital malformations. Selection criteria of control parturients who gave birth to infants with normal weight: a.Choose the gestational week born in the same hospital $>28$ weeks, body weight $>2500 \mathrm{~g}$, difference in birth time $<7 \mathrm{~d}$, singleton normal live birth infants;

b.Excluding pregnant women and pregnant women with complications and complications during pregnancy newborn. Comparing the general data of the two groups, the difference was not statistically significant $(P \otimes 0.05)$.

\section{Serum folate levels}

The fasting venous blood of the subjects was extracted, the serum was separated in time and placed in the refrigerator at $-20{ }^{\circ} \mathrm{C}$ for examination. The serum folate level was measured by chemiluminescence method with Abbott i2000R(Abbott ,USA) .

\section{DNA Extraction and Genotyping}

We extracted DNA from $2 \mathrm{~mL}$ whole blood, which was collected in ethylenediaminetetraacetic acid (EDTA) and stored at $-20^{\circ} \mathrm{Cbased}$ on provided instructions(Nucleic Acid Extraction and Purification Kit, 
Kuangyuan Bio.,Suzhou,China). Polymorphisms MTHFR C677T, A1298C and MTRR A66G were typed in an allele-specific polymerase chain reaction (ASPCR) assay combined with TaqMan probe technique (Applied Biosystems, Foster City, CA,USA) with the ABI 7500 real-time PCR system (Applied Biosystems, Foster City, CA,USA). A sample of the PCR system contained $2 \mu$ of genomic DNA, $22 \mu$ of amplification reagent that included labelled primer pairs (MTHFR gene detection kit; Kuangyuan Bio.,Suzhou,China), and $1 \mu$ l of reaction solution A (MTHFR gene detection kit; Kuangyuan Bio.,Suzhou,China). The positive controls (TT genotype) and negative controls (MTHFR gene detection kit; Kuangyuan Bio.,Suzhou,China) were amplified at the same time. The amplification steps were $50^{\circ} \mathrm{C}$ for $2 \mathrm{~min}, 95^{\circ} \mathrm{Cfor} 3 \mathrm{~min}$, and 45 cycles of the following steps: $95^{\circ} \mathrm{C}$ for $10 \mathrm{~s}, 56^{\circ} \mathrm{Cfor} 30 \mathrm{~s}$, and $60^{\circ} \mathrm{C}$ for $30 \mathrm{~s}$. Fluorescence signal was collected in the last 35 amplification cycles.Finally, the type of MTHFR C677T, A1298C and MTRR A66G genotype was determined according to the number of cycles (CT value) of the fluorescence signal forming the amplification curve at a specific threshold. The main parameters for ASPCR of the three single nucleotide polymorphisms (SNPs) were shown in Table 1.

Table 1

Primer sequences for MTHFR C677T, A1298C and MTRR A66G polymorphisms.

\begin{tabular}{|lll|}
\hline Gene & Primer sequence $^{1}$ & Product Size \\
\hline MTHFR C677T & F: 5'-TGAAGGAGAAGGTGTCTGCGGGA-3' & 198bp \\
& R: 5'-AGGACGGTGCGGTGAGAGTG-3' & \\
\hline MTHFRA1298C & F: 5'-CTTTGGGGAGCTGAAGGACTACTAC-3' & 163bp \\
& R: 5'-CACTTTGTGACCATTCCGGTTTG-3' & \\
\hline MTRR A66G & F: 5'-GCAAAGGCCATCGCAGAAGACAT-3' & 151bp \\
\hline & R: 5'-GTGAAGATCTGCAGAAAATCCATGTA-3' & \\
\hline 1'F: forward primer; R: reverse primer. & \\
\hline
\end{tabular}

\section{Statistical Analysis}

The relationship between MTHFR C677T, A1298C and MTRR A66G polymorphisms and LBW used SPSS v22.0 (IBM, Inc., Armonk, NY, USA) for statistical testing in our study.Quantitative data were expressed as mean \pm standard deviation ( $(\mathrm{x} \pm \mathrm{s}$ ) and qualitative data as $\mathrm{n}(\%)$.Comparisons of difference between the case and control with respect to general characteristics were performed by two-sample $t$ test and Chisquare $\left(\chi^{2}\right)$ test, respectively.Analysis of variance was used for multi group comparison. Unconditional logistic regression analysis was used to evaluate the associations of multi-factors and the three polymorphisms by Odds ratios (OR) and $95 \%$ confidence interval $(\mathrm{Cl})$. The trend test was used to verify the above results.Hardy-Weinberg equilibrium (HWE) was also assessed for the distributions of 
genotypes with $\chi^{2}$ test between cases and controls. A two sided $p$ value below 0.05 was considered statistical significance.

\section{Results}

\section{Population characteristics}

Table 2 summarizes the clinical characteristics of the cases and controls.A total of 106 low birth weight infants were collected, of which 63 were males and 43 were females. The birth weight was

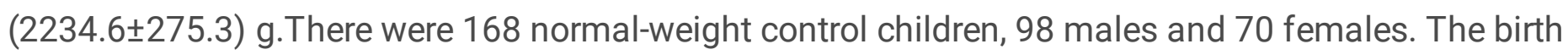
weight was $(3374.7 \pm 523.4) \mathrm{g}$. Two-sample $t$ test and $X^{2}$ test showed that there were statistically significant in infant birth weight, gestational week of delivery, maternal serum folate level, blood pressure, heart rate and alcohol intake during pregnancy between the two groups $(P<0.05)$. 
Table 2

Clinical characteristics of case and controls.

\begin{tabular}{|c|c|c|c|}
\hline \multirow[t]{2}{*}{ Variable } & Case $(\mathrm{N}=106)$ & Control $(\mathrm{N}=168)$ & \multirow[t]{2}{*}{$P$} \\
\hline & $N(\%) / \bar{x} \pm s$ & $N(\%) / \bar{x} \pm s$ & \\
\hline Maternal age, year & $32.37 \pm 10.10$ & $31.38 \pm 9.40$ & $>0.05$ \\
\hline Maternal Height, cm & $160.1 \pm 4.8$ & $160.8 \pm 4.1$ & $>0.05$ \\
\hline Prepregnancy weight, kg & $53.9 \pm 7.5$ & $55.6 \pm 7.6$ & $>0.05$ \\
\hline Maternal serum folate, $\mathrm{nmol} / \mathrm{L}$ & $12.5 \pm 1.5$ & $16.9 \pm 1.0$ & $<0.05$ \\
\hline SBP, mmHg & $128.3 \pm 14.9$ & $117.9 \pm 9.5$ & $<0.05$ \\
\hline $\mathrm{DBP}, \mathrm{mmHg}$ & $84.3 \pm 10.2$ & $79.2 \pm 3.0$ & $<0.05$ \\
\hline $\mathrm{FBG}, \mathrm{mmol} / \mathrm{L}$ & $4.88 \pm 1.20$ & $4.92 \pm 0.95$ & $>0.05$ \\
\hline HR, Times/min & $81.3 \pm 4.4$ & $75.4 \pm 2.8$ & $<0.05$ \\
\hline Gestational week of delivery & $38.3 \pm 4.2$ & $39.9 \pm 1.8$ & $<0.05$ \\
\hline Infant birth weight,g & $2234.6 \pm 275.3$ & $3374.7 \pm 523.4$ & $<0.05$ \\
\hline Number of pregnancies & & & $>0.05$ \\
\hline 1 & 75(70.7) & 138(70.8) & \\
\hline 2 & $29(27.3)$ & $57(29.2)$ & \\
\hline Infant sex & & & $>0.05$ \\
\hline Male & $63(59.4)$ & $98(58.3)$ & \\
\hline Female & $43(40.6)$ & $70(41.7)$ & \\
\hline Alcohol intake during pregnancy & & & $<0.05$ \\
\hline No & $90(88.8)$ & 159(94.6) & \\
\hline Yes & 16(15.1) & $9(5.3)$ & \\
\hline Tobacco smoking during pregnancy & & & $>0.05$ \\
\hline Nonsmoker & $57(53.7)$ & $97(57.7)$ & \\
\hline Passive smoker & $46(43.3)$ & $65(38.7)$ & \\
\hline Smoker & $3(3.0)$ & $6(3.6)$ & \\
\hline
\end{tabular}




\section{Gene distribution}

In this study, the HWE test was used to verify the reliability of the specimen. The results showed that the collected MTHFR C677T, A1298C, and MTRR A66G gene polymorphisms in the population of Northeast China are in line with genetic balance. The data came from the same Mendelian group, and the specimens were regionally representative.

\section{Association between gene polymorphisms and LBW}

The genotypic frequencies of MTHFR C677T, A1298C and MTRR A66G were shown in Table 3. MTHFR 677 TT and 1298CC genotype were more prevalent in cases than in controls $(49.1 \%$ vs $29.2 \% ; 13.2 \%$ vs $5.3 \%$,repetitively). There was significant difference in the distribution of genotype between cases and controls, with ORs of 2.22(95\% Cl:1.14-4.34, P = 0.02) and 1.94(95\% Cl: 1.66-3.21, P=0.01) for 677TT, when compared with CC and CC + CT, respectively.Similarly, a significant difference in 1298CC genotype distribution were also found between the two study groups, with ORs of 2.82(95\% Cl:1.15-6.87, P = 0.02) when compared with AA genotype.The results suggest that MTHFR gene 677TT, 1298CCgenotype were associated with an increased risk of LBW.However,none significant result was found in MTRR A66G polymorphism alone. 
Table 3

Effects of gene polymorphisms on LBW

\begin{tabular}{|c|c|c|c|c|c|}
\hline Genotype & $\begin{array}{l}\text { Cases }(\mathrm{N}=106), \mathrm{n} \\
(\%)\end{array}$ & $\begin{array}{l}\text { Controls }(\mathrm{N}=168), \mathrm{n} \\
(\%)\end{array}$ & OR $(95 \% \mathrm{Cl})^{\mathrm{a}}$ & $P$ & HWE \\
\hline MTHFR C677T & & & & & 0.17 \\
\hline $\mathrm{CC}$ & 19(12.3) & $44(25.0)$ & Reference & & \\
\hline СT & $40(38.6)$ & $75(44.6)$ & $\begin{array}{l}1.24(0.64- \\
2.39)\end{array}$ & 0.53 & \\
\hline TT & $47(49.1)$ & $49(29.2)$ & $\begin{array}{l}2.22(1.14- \\
4.34)\end{array}$ & 0.02 & \\
\hline $\mathrm{CC}+\mathrm{CT}$ & $59(50.9)$ & 119(70.8) & Reference & & \\
\hline TT & $47(49.1)$ & 49(29.2) & $\begin{array}{l}1.94(1.66- \\
3.21)\end{array}$ & 0.01 & \\
\hline $\begin{array}{l}\text { MTHFR } \\
\text { A1298C }\end{array}$ & & & & & 0.12 \\
\hline AA & $63(59.4)$ & 114(67.9) & Reference & & \\
\hline AC & $29(27.4)$ & $45(26.8)$ & $\begin{array}{l}1.17(0.67- \\
2.04)\end{array}$ & 0.59 & \\
\hline $\mathrm{CC}$ & $14(13.2)$ & $9(5.3)$ & $\begin{array}{l}2.82(1.15- \\
6.87)\end{array}$ & 0.02 & \\
\hline$A A$ & $63(59.4)$ & 114(67.9) & Reference & & \\
\hline$A C+C C$ & $43(40.6)$ & $54(32.1)$ & $\begin{array}{l}1.44(0.87- \\
2.39)\end{array}$ & 0.16 & \\
\hline MTRR A66G & & & & & 0.68 \\
\hline $\mathrm{AA}$ & $49(46.2)$ & $84(50.0)$ & Reference & & \\
\hline AG & $39(36.8)$ & $68(40.5)$ & $\begin{array}{l}0.98(0.58- \\
1.67)\end{array}$ & 0.95 & \\
\hline GG & 18(17.0) & $16(9.5)$ & $\begin{array}{l}1.93(0.90- \\
4.12)\end{array}$ & 0.09 & \\
\hline AA & $49(46.2)$ & $84(50.0)$ & Reference & & \\
\hline$A G+G G$ & $57(71.7)$ & $84(50.0)$ & $\begin{array}{l}1.16(0.72- \\
1.70)\end{array}$ & 0.54 & \\
\hline
\end{tabular}




\section{Association between genetic interaction and LBW}

The joint effects of MTHFR C677T, A1298C and MTRR A66G polymorphisms on LBW were next examined (Table 4). None of the study subjects had the 677TT/1298AC + CC genotypes. When compared with the 677CC + CT/1298AA, the cases with the 677CC + CT/1298AC + CC and 677TT/1298AA genotypes had higher odds of LBW risk $(\mathrm{OR}=3.24,95 \% \mathrm{Cl} 1.64-6.37, \mathrm{p}=0.00 ; \mathrm{OR}=3.90,95 \% \mathrm{Cl} 1.98$ $7.67, \mathrm{p}=0.00$;repetitively).Moreover, the $677 \mathrm{CC}+\mathrm{CT} / 66 \mathrm{AG}+\mathrm{GG}$ and $677 \mathrm{TT} / 66 \mathrm{AG}+\mathrm{GG}$ carriers both had higher risks of LBW compared with the reference group $(\mathrm{OR}=2.08,95 \% \mathrm{Cl} 1.11-3.93, \mathrm{p}=0.02 ; \mathrm{OR}=7.68$, $95 \% \mathrm{Cl} 3.43-17.17, \mathrm{p}=0.00$,repetitively). The trend test was further performed to verify these results, MTHFR C677T/MTHFR C677T and MTHFR C677T/MTRR A66G combinations dramatically increased the LBW risk.

Table 4

Effects of gene-gene interactions on LBW

\begin{tabular}{|llllll|}
\hline Genotype 1 & Genotype 2 & Case/Control & OR $(95 \% \mathrm{Cl})$ & $P$ & $P_{t}$ \\
\hline MTHFR C677T & MTHFR A1298C & & & \\
\hline CC + CT & AA & $16 / 65$ & Reference & & 0.00 \\
\hline CC + CT & AC + CC & $43 / 54$ & $3.24(1.64-6.37)$ & 0.00 & \\
\hline TT & AA & $47 / 49$ & $3.90(1.98-7.67)$ & 0.00 & \\
\hline TT & AC + CC & $0 / 0$ & - & - & \\
\hline MTHFR C677T & MTRR A66G & & & & \\
\hline CC + CT & AA & $25 / 72$ & Reference & & \\
\hline CC + CT & AG + GG & $34 / 47$ & $2.08(1.11-3.93)$ & 0.02 & \\
\hline TT & AA & $15 / 37$ & $1.17(0.55-2.48)$ & 0.69 & \\
\hline TT & AG + GG & $32 / 12$ & $7.68(3.43-17.17)$ & 0.00 & \\
\hline MTHFR A1298C & MTRR A66G & & & & \\
\hline AC + CC & AA & $22 / 26$ & Reference & & \\
\hline AC + CC & AG + GG & $21 / 28$ & $0.89(0.40-1.98)$ & 0.77 & \\
\hline AA & AA & $27 / 58$ & $0.55(0.27-1.14)$ & 0.11 & \\
\hline AA & AG + GG & $36 / 56$ & $0.76(0.38-1.54)$ & 0.45 & \\
\hline $\begin{array}{l}\text { a Adjusted for Maternal age,Height, weight, serum folate, SBP,DBP,FBG,HR,Gestational week of } \\
\text { delivery, Infant birth weight. }\end{array}$ & & & & \\
\hline$P_{t: \text { P value of trend test. }}$ & & & & \\
\hline
\end{tabular}




\section{Discussion}

LBW is the result of premature delivery and intrauterine growth retardation. At present, the etiology of LBW mainly focuses on maternal diseases and infections, behavioral risk factors and social demographics.Studies at home and abroad have shown that multiple births, insufficient gestational weeks, poor nutrition during pregnancy, history of maternal diseases, umbilical cord abnormalities, history of dysmenorrhea and mental stimulation during pregnancy are risk factors for the occurrence of LBW[22-24]. In view of the importance of genetic factors, a more comprehensive analysis of the risk factors of LBW should be made in conjunction with environmental factors and genetic factors.

As studies have found that hyperHcyemia can induce certain diseases such as congenital malformations and cardiovascular diseases[25-27].Hcy is a sulfur-containing amino acid whose metabolism is affected by three key enzymes such as MTHFR, as well as folic acid and a variety of vitamins [28].5-

Methylenetetrahydrofolate is the methyl donor for Hcy methylation. MTHFR plays an important role in the conversion of 5,10-methylenetetrahydrofolate to 5-methylenetetrahydrofolate. Therefore, MTHFR can indirectly regulate the plasma Hcy level [29 ].The MTHFR gene C677T can cause the originally synthesized alanine to become valine, thereby reducing the enzyme activity, leading to the hindrance of Hcy metabolism, and which finally causing hyperhomocystinemia (Hhcy)[30].The maternal blood circulation is connected to the fetus through the placenta. Hhcy will also be manifested in the fetal blood circulation, which can cause fetal blood vessel development abnormalities, neural tube development abnormalities, and premature delivery. This may be one of the reasons for the LBW of the fetus.

After adjusting the confounding factors,our analysis showed that MTHFR 677TT and 1298CC were independently associated with a higher risk of LBW. The MTRR A66G polymorphism was associated with an significant association with LBW when combined with the MTHFR 677TT genotype, but no association was found between LBW and MTRR A66G alone.Moreover, two or more risk genotypes carriers showed higher odds of LBW than null risk genotype one.In line with the above mechanism our data indicate MTHFR 677TT and 1298CC that affects key enzymes in the Hcy metabolic pathway is an independent risk factor for LBW.Additionally, judging from the results of the interaction analysis, it is suggested that the joint action of multiple gene polymorphisms will increase the risk of LBW.

There were several studies on the correlation between folic acid metabolism gene polymorphisms and LBW, which included low birth weight live birth babies as the case group[31-32]. However, in our study we used maternal blood samples of parturients who gave birth to low birth weight infants as the case group, because we wanted to achieve primary prevention of LBW and screen high-risk pregnant women by identifying the maternal MTHFR C677T and MTRR mutations.As far as we know, we are the first to prove that MTHFR C677T, MTHFR A1298C and MTRR A66G gene polymorphisms affect the risk of LBW in Northeast China.The limitation of our study is that the sample size is relatively small. Therefore, we believe that large sample studies can be carried out in the future to verify our results in a wider population

\section{Conclusions}


In conclusion,our study found that maternal MTHFR gene 677TT, 1298CC can increase the risk of LBW in the offspring.The MTRR A66G polymorphism was not associated with LBW alone. But it may exacerbate the effect of the MTHFR C677T variant .Further large prospective population-based studies are required to confirm our findings.

\section{Abbreviations}

MTHFR, maternal methylenetetrahydrofolate reductase; LBW, low birth weight; MTRR, Methionine Synthase Reductase; ASPCR, Allele-specific polymerase chain reaction; Hcy, homocysteine; EDTA, ethylenediaminetetraacetic acid; SNPs, single nucleotide polymorphisms; HWE, Hardy-Weinberg equilibrium; SPSS, Statistical Package for the Social Science; ORs, odds ratios; Cls, Hhcy, confidence intervals; hyperhomocystinemia.

\section{Declarations}

\section{Acknowledgements}

Not applicable

\section{Funding}

This research was supported by Dean Fund of Jilin Province Maternal and Child Health Hospital.

\section{Availability of data and materials}

The datasets used and/or analysed during the current study are available from the corresponding author on reasonable request.

\section{Ethics approval and consent to participate}

All procedures conducted in this study involving human participants complied with the ethical standards of the Handbook for Good Clinical Research Practice of the World Health Organization and the Declaration of Helsinki principles (https://www.wma.net/policies-post/wma-declaration-of-helsinkiethical-principles-for-medical-research-involving-human-subjects/). The experimental protocol was established, according to the ethical guidelines of the Helsinki Declaration and was approved by the Institutional Review Board (IRB) ofMaternal and Child Health Hospital of Jilin Province, China. Written informed consent was obtained from all subjects.

\section{Consent for publication}

Not applicable.

\section{Competing interests}


The authors declare that they have no competing interests.

\section{Author Contribution}

Each author's contribution(s) to the manuscript, using the numbered list below:

1. Research concept and design: Shuang Sun

2. Collection and/or assembly of data: Shuang Sun

3. Data analysis and interpretation: Shuang Sun

4. Writing the article: Shuang Sun

5. Critical revision of the article:Ying Liu and Xiaoling $\mathrm{Hu}$

6. Final approval of article:Ying Liu and Xiaoling $\mathrm{Hu}$

7. Table editing: Xun Zhao and Xuehua Guo

\section{References}

1. Cai Shixiang. Long-term investigation and analysis of intelligent development and adaptive behavior in low birth weight infants. Chinese Journal of Eugenics and Genetics, 2002, 10(1): 91-91.

2. Lin Liangming, Liu Yulin, Zhang Xinli, et al. Results of a sample survey of low birth weight infants in China. Chinese Journal of Preventive Medicine, 2002, 36(3): 149-153.

3. PINZ ON -RO ND ON A-M,GUTI ERREZ -PINZON V,MADRINAN -AVIA H,et al. Low birth weight and prenatal care in Colombia:a cross-sectional study . Bmc Pregnancy \& Childbirth,2015,15(1):1-7.

4. DORITSAKOU K,LIOSIS G,VALSAMI G,et al. Improved outcomes of feeding low birth weight infants with predominantly raw human milk versus donor banked milk and formula . J Matern Fetal Neonatal Med,2016,29(7):1131-1138.

5. FrosstP, BlomHJ, MilosR, et a1.A candidate genetic risk factorfor vascular disease:a common mutation in methylenetetrahydrofolatel reductase.NatGenet,1995,10(1):111-113.

6. Whitehead AS, Gallagher P, Mills JL,et a1.A genetic defectin 5,10 methylenetetrahydrofolate reductase in neural tube defects. QJM,1995,88(11):763-766.

7. Frosst $\mathrm{P}$, Blom HJ, Milos R, Goyette $\mathrm{P}$, et al. A candidate genetic risk factor for vascular disease: a common mutation in methylenetetrahydrofolate reductase. Nat Genet. 1995;10:111-3.

8. Engbersen, A.M.T., Franken, D. G., Boers, G.H.J., Stevens, E.M.B., Trijbels,F. J. M. \& Blom, H. J. Thermolabile 5,10-methylenetetrahydrofolate reductase as a cause of mild hyperhomocysteinemia. Am. J. Hum. Genet.1995;56:142-150.

9. Frosst, P., Blim, H. J., Milos, R., Goyette, P., Sheppard, C. A., Matthews, R. G.,Boers, G.J.H., den Heijer, M., Kluijtmans, L.A.J., van den Heuvel, L. P. \&Rozen, R. A candidate genetic risk factor for vascular 
disease: A common mutation in methylenetetrahydrofolate reductase. Nat. Genet. 1995 ;10:111113.

10. Jacques, P. F., Bostom, A. G., Williams, R. G., Ellison, R. C., Eckfeldt, J. H., Rosenberg, I. H., Selhub, J. \& Rozen, R. Relation between folatestatus, a common mutation in methylenetetrahydrofolate reductase, and plasma homocysteine concentrations. Circulation .1996;93: 7-9.

11. Gaughan DJ, Kluijtmans LA, Barbaux S, et al. The methionine synthase reductase (MTRR) A66G polymorphism is a novel genetic determinant of plasma homocysteine concentrations. Atherosclerosis. 2001;157:451-6.

12. Yi P, Melnyk K, Pogribna M, Pogribny IP, Hine RJ, James SJ. Increase in plasma homocysteine associated with parallel increases in plasma S-adenosylhomocysteine and lymphocyte DNA hypomethylation. J Biol Chem. 2000, 38, 29318-29323.

13. Vaughn JD,Bailey LB, Shelnutt KP, Dunwoody KM, Maneval DR, Davis SR, Quinlivan EP, Gregory JF, Kauwell GP. Methionine synthase reductase $66 \mathrm{~A} \rightarrow \mathrm{G}$ polymorphism is associated with increased plasma homocysteine concentration when combined with the homozygous methylenetetrahydrofolate reductase $677 C \rightarrow$ T variant. J. Nutr. 2004, 134, 2985-2990.

14. Richter B, Stegmann K, Röper B, Böddeker I, Ngo ET, Koch MC. Interaction of folate and homocysteine pathway genotypes evaluated in susceptibility to neural tube defects (NTD) in a German population. J Hum Genet. 2001;46(3):105-9.

15. Chango A, Fillon-Emery N, Mircher C, Bléhaut H, Lambert D, Herbeth B, et al. No association between common polymor[1]phisms in genes of folate and homocysteine metabolism and the risk of Down's syndrome among French mothers. Br J Nutr.2005;94:166-9.

16. Van der Put NM, Gabreëls F, Stevens EM, Smeitink JA, Trijbels FJ, Eskes TK, et al. A second common mutation in the methylenetetrahydrofolate reductase gene: an additional risk factor for neural-tube defects? Am J Hum Genet. 1998;62:1044-51.

17. Gideon Friedman,Netta Goldschmidt,Yechiel Friedlander,et al.A Common Mutation A1298C in Human Methylenetetrahydrofolate Reductase Gene: Association with Plasma Total Homocysteine and Folate Concentrations.J Nutr.1999;129(9):1656-61.

18. Ueland PM, Rozen R. MTHFR Polymorphisms and Disease. 1st ed. Landes Bioscience: Texas; 2005.

19. Liew SC, Gupta ED. Methylenetetrahydrofolate reductase (MTHFR) C677T polymorphism: epidemiology, metabolism and the associated diseases. Eur J Med Genet 2015;58:1-0.

20. Yang B, Fan S, Zhi X, et al. Associations of MTHFR gene polymorphisms with hypertension and hypertension in pregnancy: a meta-analysis from 114 studies with 15411 cases and 21970 controls. PLoS One 2014;9:e87497.

21. Tiwari, D. et al. MTHFR (C677T) polymorphism and PR (PROGINS) mutation as genetic factors for preterm delivery, fetal death and low birth weight: A Northeast Indian population based study. Meta Gene 3, 31-42 (2015).

22. Zhang Xinli, Liu Yulin, Lin Liangming, etc. A case-controlled study of risk factors for low birth weight infants in China. Chinese Journal of Preventive Medicine, 2002, 36(3): 158-160. 
23. Lin Ling, et al. A case-control study on the risk factors of term low birth weight infants in Changning District, Shanghai. Environmental and Occupational Medicine, 2008, 25(2): 163-170.

24. Mushy CC,et a1.Abuse:a risk factor for low birth weight?A system- atic review and metaanalysis.CMAJ,2001,164(11):1567.

25. MillsJL,et a1.Homocysteine metabolism in pregnancies complicated byneuraltubedefects.Lancet,1995,345(8943)149-151.

26. Jacobsen DW.Homocysteine and vitamins in cardiovasculardisease.Clinical Chemistry,1998,44(8Pt2)1833-1843.

27. McCully KS. Hyperhomocysteinemia and arteriosclerosis:historical perspectives.Clin Chem Lab Med,2005,43(10):980-986.

28. Du Jingyun, Yang Xinxin, Gong Bo, etc. Correlation between plasma homocysteine, folic acid and MTHFR gene polymorphisms and preterm birth. Journal of Sun Yat-sen University: Medical Science Edition, 2013, 34(6): 894-899.

29. Dell'Edera D,L'Episcopia A,Simone F,et al.Methylenete trahydrofolate reductase gene C677T and A1298C polymorphisms and susceptibility to recurrent pregnancy loss .Biomed Rep,2018,8(2):172175.

30. Wang BJ,Liu MJ,Wang Y,et al.Association between SNPs in genes involved in folate metabolism and preterm birth risk.Genet Mol Res,2015,14(1):850-859.

31. Zhong QA, Qiu XQ, Zeng XY, Deng YY, Wu TY .Association of low birth weight with genetic polymorphism of MTHFR and CBS in mother. Chin J Birth Health Hered .2009;17 (3):22-24.

32. Wu Di, Li Jing, Yang YF,et al. Guan Mingjie 3Association between genetic polymorphisms of MTHFR gene in mother and low birth weight in the newborn.Chinese Journal of reproductive health.2009;6:352-355. 